\title{
PAULO FREIRE, ANDARILHO DO MUNDO, DE REGRESSO AO SEU POVO, DE VOLTA AO SEU PAÍS!
}

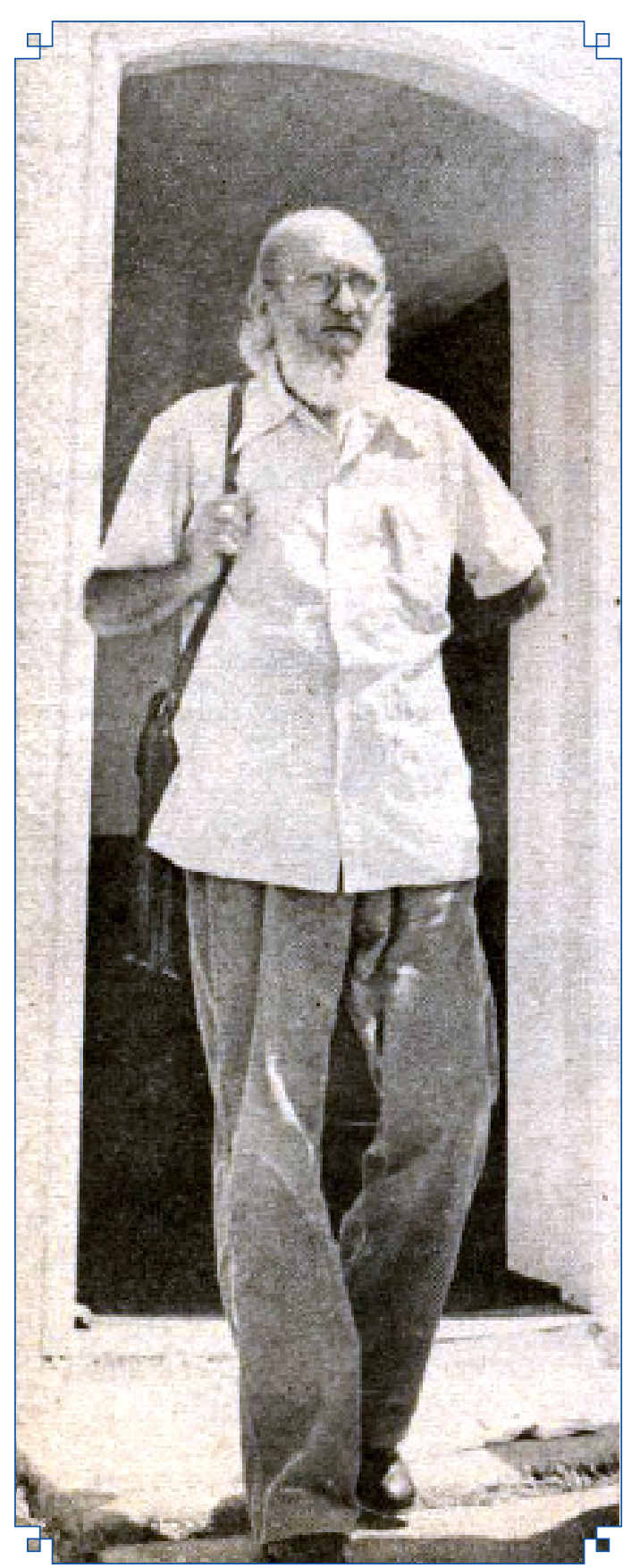

Figura 1. Paulo Freire quando retornou ao Brasil

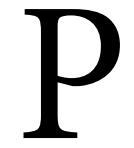

aulo Freire retorna ao seu país, após longo exílio, que o forçou a viver no exterior. O golpe civil militar de 1964 ocorrido no Brasil afastou Freire dos seus trabalhos na universidade, nos círculos de cultura e no Programa Nacional de Alfabetização de Adultos. Também interrompeu seus contatos com os familiares, os amigos e o povo brasileiro, os quais o educador amava de coração aberto. Freire foi levado a aprender a conviver com outros povos - americanos por curto período, europeus e, sobretudo, africanos, de países nos quais suas teoria e metodologia são abraçadas com força, crédito, limites e coragem!

Convidado, em 1978, para abrir o I Seminário de Educação Brasileira, organizado pela Faculdade de Educação da Unicamp, Paulo Freire, impedido de estar presente, enviou para os participantes, por telefone, a seguinte mensagem:

Eu gostaria de dizer aos companheiros, aos amigos que estão aí, agora, no Seminário de Educação Brasileira, da minha emoção imensa, fantástica, que me toma, de estar falando aos professores brasileiros, aos educadores brasileiros, do apartamento em que vivo, aqui em Genebra, cercado de meus filhos e de quatro grandes amigos brasileiros que, por coincidência, encontram-se entre nós.

É uma alegria enorme me servir da possibilidade que a tecnologia me coloca à disposição, hoje, de gravar, de tão longe de vocês, essa palavra que não pode ser outra senão uma palavra afetiva, uma palavra de amor, uma palavra de carinho, uma palavra de confiança, de esperança e de saudades também, saudade imensa, grandona, saudades do Brasil gostoso, desse Brasil de nós todos, desse Brasil cheiroso, distante do qual estamos há catorze anos, mas distante do qual nunca estivemos também.

1.Universidade Estadual de Campinas - Faculdade de Educação e Centro de Estudos, Educação e Sociedade - Campinas (SP), Brasil. E-mail: ivanypino@gmail.com 
Evidentemente, no momento, quando o professor Gadotti, meu querido amigo, com quem convivi aqui em Genebra, me pede que eu diga alguma coisa, é claro que vocês não podem esperar de mim uma reflexão pedagógica, política, epistemológica. Seria falso. Seria inviável para mim agora pensar criticamente, refletir sobre a pedagogia brasileira, sobre os desafios que nós temos.

Eu confesso que não poderia fazer isso. Mas também não pude negar ao professor Gadotti de mandar esse recado por telefone e lamentar não poder estar aí com vocês nesse momento em que se realiza o Seminário de Educação Brasileira. Eu só não estou aí porque, afinal de contas, eu não tenho um passaporte. Faz catorze anos que eu peço esse passaporte e esse passaporte não me foi dado. Nem o "ficaporte", quer dizer, esse extravagante passaporte dentro do qual se escreve que ele é válido só para a cidade onde a pessoa mora, como o "ficaporte" que deram para minha mulher. Nem esse eu tenho. É por isso que eu não estou aí, mas espero que um dia eu tenha o "passa-porte" e aí eu voltarei ao Brasil para abraçá-los e para dizer mais uma vez o quanto brasileiro eu sou, o quanto brasileiro tenho continuado a ser apesar da distância em que estamos no tempo e no espaço.

Meu grande abraço para vocês e que o Seminário seja um êxito, um êxito para todos nós, para o povo brasileiro e para o futuro da educação nacional (PAULO FREIRE, 1978, por telefone).

De volta ao Brasil, o educador trazia consigo imagens, fantasias, desejos, imaginação e vontade de retomar seus trabalhos pessoais e acadêmicos, concretizados em equipes, conversas e diálogos, círculos de cultura impedidos e interrompidos violentamente pela ditadura do Estado militar. Nesses novos tempo e espaço de sua vida, de regresso ao seu povo, de volta ao seu país, parte da experiência de Paulo Freire como andarilho do mundo foi acolhida na Unicamp, na Faculdade de Educação, no Departamento de Ciências Sociais Aplicadas à Educação (DECISAE), na convivência da vida acadêmica com jovens em salas de aula, com professores e pesquisadores seus colegas, em seminários com alunos da pós-graduação e, inclusive, nas reuniões de departamento que eu coordenava, então no cargo de chefe do departamento e no CEDES (Fig. 1).

Com amor e paciência, que sempre cunhavam sua presença, Paulo falava e opinava sobre os diferentes temas e colegas, independentemente de posições teóricas, metodológicas, político-partidárias e de nacionalidade, de suas experiências pessoais e de convívio anteriores, procurando se reintegrar a assuntos dos quais ficou tanto tempo afastado. Sua vivência na universidade extrapola as salas de aula e se expande para movimentos sociais, grupos religiosos, educação de base, teologia da libertação e agentes de saúde que atuavam nas periferias de Campinas e de São Paulo, mediante sua articulação na Faculdade de Educação da Unicamp e na PUCSP. Uma das práticas pedagógicas de Paulo Freire que eu gostaria de destacar foi sua articulação com um grupo de professores-médicos de saúde pública da Faculdade de Medicina da Unicamp, que atuavam com alunos-estagiários em um Posto de Saúde de um dos municípios de Campinas (Paulina), trabalhando com os moradores em movimentos sociais de saúde pública.

Assim, Paulo Freire retomou sua reintegração ao seu país de origem, num estado diferente do qual o deixou, como se dele jamais tivesse se afastado e jamais tivesse sofrido a dor da separação. Aos poucos, transformou em realidade os desejos que expressa nesta entrevista, com a qual a revista Educação \& Sociedade inaugura sua homenagem!

Considero oportuno deixar aqui registrado o retorno de Paulo Freire à Europa, à l'Université Catholique de Louvain-la-Neuve (UCL), em Ottignies, Wallonie, na Bélgica, nos anos de 1985, atendendo a um convite que lhe foi feito pelo então diretor do Institut "des Sciences Économiques, Sociales et Politiques", Prof. Michel Molitor. 
Naquela ocasião, Paulo Freire recebeu, da UCL, mais um título de Professor Emérito e permaneceu em nossa casa durante sua estadia na Bélgica, a convite de Angel Pino, em virtude de seu incômodo de se hospedar em hotel -única condição, aliás, para aceitar o convite. Assim, tive o privilégio de acompanhá-lo em seus múltiplos contatos com grupos latino-americanos, mas, sobretudo, africanos, que sempre o deixavam de forma carinhosa e amiga um mimo do seu país de origem como símbolo do apreço que lhe conferiam como teórico e mestre da educação popular que muito trabalhou em África.

Com vocês, o projeto de Paulo Freire ao retornar ao Brasil ${ }_{2}$ por meio da entrevista publicada no Jornal da Educação, concedida a Olavo Avalone Filho, Maria Inês Nasif e Cristina Luiza Borchert (AVALONE FILHO et al., 1980).

\section{Paulo Freire Volta a Trabalhar no Brasil em Agosto: Entrevista dada ao Jornal da Educação - CEDES (1980)}

O educador Paulo Freire deverá vir em definitivo para o Brasil no próximo dia 2 de julho. Aqui ele desenvolverá trabalhos voltados à educação popular: na Unicamp, na PUC de São Paulo e junto aos grupos da Igreja que atuam na periferia paulistana. Paulo Freire esteve 24 passado, no Centro de Estudos, Educação e Sociedade e na Faculdade de Educação da Unicamp, quando trocou ideias com educadores sobre seus planos de trabalho aqui no Brasil.

O educador brasileiro se desligará do Conselho Mundial de Igrejas, com sede em Genebra, em junho próximo, mas continuará ligado ao IDAC - Institut D’action Culturelle, órgão que ele próprio criou em Genebra, capital suíça, para desenvolver trabalhos de assessoria aos programas de educação de vários países do mundo todo. Aliás, segundo informou o próprio Paulo Freire, o IDAC será transferido para o Brasil, com sede no Rio de Janeiro.

JE - Após Campinas, qual seu destino e quando se dará seu retorno ao Brasil? O que o Sr. fará nesta viagem e depois e de voltar, agora em definitivo?

PAULO FREIRE - Vou daqui para Guiné-Bissau, onde já há quatro ou cinco anos eu venho prestando assessoria ao governo de lá, particularmente ao Ministério de Educação, ao lado dos ministérios de Cabo Verde, São Tomé e Príncipe e também em Angola. Essa assessoria eu venho dando em nome de dois motivos: de um lado, como trabalhador do Departamento de Educação do Conselho Mundial de Igrejas, onde estarei até o fim de junho, e, do outro, como membro da equipe do Instituto de Ação Cultural, que eu criei com jovens brasileiros e europeus em Genebra há oito anos atrás. E agora estou indo lá para uma visita última, porque nossa assessoria na Guiné termina agora, e nós continuaremos com Cabo Verde e São Tomé. Estou indo com a Elza, minha mulher, que trabalha comigo e da Guiné eu parto para Genebra, onde vou tratar do retorno definitivo ao Brasil, que deve se dar no dia 2 de julho deste ano.

JE - Aqui no Brasil, que atividades o sr. desenvolverá?

PAULO FREIRE - Aqui eu trabalharei em São Paulo, radicado em São Paulo, na PUC e na Unicamp. Trabalharei ao nível da pós-graduação, sem que isto signifique um corte radical quanto à graduação. Mas a minha preocupação fundamental enquanto educador trabalhando em universidade como a Unicamp e a PUC, enquanto contextos teóricos, é não cortar as minhas relações com os contextos concretos sobre os quais 
eu devo refletir no contexto teórico. Sem dicotomizar esses contextos, mas, pelo contrário, tornando-os sempre dinamicamente. Por outro lado, tudo indica que nós vamos trabalhar também com a equipe do IDAC, cuja inserção no Brasil nós estamos estudando. Nós vamos também trabalhar um pouco num tipo de assessoria às equipes de Dom Paulo Evaristo. Não nós diretamente na periferia de São Paulo, mas trabalhando com as equipes que atuam nas unidades de base. No meu caso particular vai nos dar uma possibilidade muito grande de reflexão sobre algo muito real, muito concreto. Porque com este tipo de trabalho eu estou tendo também contato com diferentes instituições com cujas equipes eu começo já a estabelecer um bom tipo de relação, como por exemplo as equipes do CEDEC e do CEDES, com as quais nós vamos trabalhar muito juntos. O CEDEC ofereceu-me até uma sala para ficar lá, com minha mulher, dentro dum horário, enquanto não estiver aqui ou na PUC. Quer dizer, há um horizonte muito amplo e vasto de trabalho disponível, sério, que se clareará na medida em que eu chegue e comece a trabalhar. Será exatamente a prática que me vai delimitar inclusive os campos meus, será a minha prática que vai me dizer, aqui tu estavas pensando sonhadoramente, não podes, aqui tu podes, etc. E por esta prática, que começará mais concretamente em agosto próximo, eu estou ansioso hoje.

JE - O Brasil encontra-se em fase de reorganização partidária e o sr., como educador talvez não se filie a determinado partido, mas certamente sendo um educador, tem opinião formada. Gostaríamos de saber se o sr. nutre simpatia por algum partido e qual ele é?

PAULO FREIRE - É, eu gostei dessa pergunta. Porque, como educador eu não posso deixar de ser político. Agora, há uma diferença: há políticos que são educadores porque são políticos e eu, como educador, sou político porque sou educador. Há uma diferença sutil, mas que não me permite de maneira nenhuma ter a pretensão que eu jamais tive, de ser neutro porque sou educador. Não há educador neutro. Mas tem um dado que eu quero te contar: eu quero me manter, tanto quanto possível, equidistante, mas não ausente, de uma ativação partidária. Mas em Genebra, há um mês ou dois atrás, eu passei um telegrama - inclusive foi a primeira, a primeira vez em minha vida particular que eu tomei uma decisão como essa, que me explicitei em torno de um partido - passei um telegrama ao PT dando minha solidariedade ao seu sonho e autorizando a usar o meu nome. Foi a primeira vez na história minha. E se você agora me pergunta: e por quê? Porque eu acho que o PT - sem entrar em consideração em torno de nenhum dos partidos que se organizam por aí - eu acho que o PT, para mim pelo menos, encarna assim uma espécie de sonho, possível, com o qual eu gosto de estar. O PT me anuncia, por exemplo, uma ação e uma reflexão política partindo de baixo para cima, como um corte de baixo para cima, que é o que eu defendo enquanto educador político. E, para terminar, eu te diria: eu acho uma certa coincidência - talvez seja uma pretensão de minha parte; eu não gosto de ser pretensioso - eu encontro uma certa coincidência entre o sonho que o PT anuncia e os meus sonhos nos meus livros. "Pedagogia do Oprimido" eu acho que tem muito a ver com o sonho do PT.

JE - Ao chegar ao Brasil, do exílio, o sr. preferiu não abordar certas questões dizendo sentir necessidade de antes reaprender o seu país. Como se sente hoje? O sr. já se sente em condições de agora falar daquelas questões?

PAULO FREIRE - Eu confesso, nisto eu também sou muito rigoroso. Evidentemente, desta vez eu já comecei a falar um pouco mais. Eu tive chance de ouvir o povão na periferia de São Paulo. Então, o processo de aprendizagem de que eu te falava no ano passado começou a se dar mais fortemente agora que no ano passado. Porque no ano passado passei um mês, primeiro sob o impacto emocional de uma volta, segundo 
dividindo esse mês entre quatro lugares do Brasil: São Paulo, Rio, Campos e Recife. Foi muito impacto, mas agora, um mês todo em São Paulo, maciamente quase, sem anúncio de que eu estava aqui, etc... Então eu tive mais tempo de pensar, de ver e de ouvir. E começo a aprender muito. Depois que eu chegar aqui, de vez, você pode fazer as perguntas que você tem.

JE - O que é o Conselho Mundial de Igrejas e qual o seu trabalho lá?

PAULO FREIRE - Faz dez anos que eu trabalho lá e não sou capaz de responder bem. Diria que o Conselho, como o próprio nome diz, é um Conselho ecumênico, que congrega uma grande quantidade de Igrejas do mundo todo. Tem sua sede em Genebra, é mantido pelas Igrejas, com mais ênfase para as Igrejas dos países mais ricos - as Igrejas alemãs, norte-americanas, sem esconder outras. Mas esta parte de administração eu também não entendo. O importante é dizer que as Igrejas mantêm o Conselho. O Conselho se divide, do ponto vista da administração, em Unidades e por número: Unidade Primeira, Unidade Segunda, etc. Eu faço parta da Terceira Unidade, meu setor. Essas Unidades, então, têm sub-unidades que se dividem em função de certos temas e de certas práticas. Então você vai encontrar, por exemplo, Unidades com sub-unidades que tratam, por exemplo, do problema de fé e sociedade, a sub-unidade que trata do combate ao racismo... Isto é que eu acho formidável no Conselho Mundial de Igrejas: em sendo uma organização da Igreja e ecumênica - não sei se com o que eu vou dizer agora vou chocar algumas pessoas do próprio Conselho - mas eu diria que o Conselho não faz a separação impossível no meu entender, entre mundaneidade e transcendentalidade, entre história e meta-história. O que significa que o Conselho ao mesmo tempo se preocupa com o problema da fé e com o problema do racismo. Ao mesmo tempo que ele se preocupa com o problema do apostolado, ele se preocupa, por exemplo, com o problema da educação de adultos, não no campo específico da Igreja. Eu, por exemplo, assessorei até agora a governos como estes governos de antigas colônias portuguesas. Se preocupa, por exemplo, com o problema do desenvolvimento. Há um setor, lá, este inclusive orientado por um jovem economista brasileiro e que estuda as multinacionais, o papel das multinacionais no mundo, seu poder, etc. Quer dizer que há, então, esta pluralidade de aspectos, o que constitui para mim uma coisa profundamente simpática. Inclusive trabalhei dez anos no Conselho Mundial de Igreja e me senti sempre muito livre, muito à vontade e nada beato. Quer dizer, não há assim uma pieguice de sacristia, de igreja, há uma preocupação assim muito séria com a vida, com a melhoria da vida. Não se dicotomiza a fé da política. Cientificamente é impossível dicotomizar, mas teoricamente é possível. Quer dizer, você também vê que não é possível separar prática da teoria, no entanto as universidades separam. Evidentemente eu não tenho autoridade para falar em nome do Conselho Mundial de Igrejas, mas estou salientando o acerto nesta postura do Conselho. Estou falando isto aqui em meu nome pessoal. Eu assumo a responsabilidade da minha leitura diante do Conselho Mundial de Igrejas. Não posso dizer que represento o Conselho.

JE - Pelo que se nota hoje há uma diferença básica na ação voltada à educação popular. No passado, pensava-se numa dimensão nacional; hoje pensa-se na ação local. A idéia do alcance da ação é nacional mas a prática é local. O sr. concorda com isto?

PAULO FREIRE - Você diz o conteúdo das ações, por exemplo?

JE - Sim.

PAULO FREIRE - Sim, estou totalmente de acordo com isto. O problema que para mim se colocaria seria 
o seguinte: a prática centrada em temas e em problemas locais, porém com uma visão nacional destes problemas. Quer dizer, ao mesmo tempo que tu discutirás, por exemplo, com uma população periférica em Campinas, teu ponto de partida é problemática daquela população, não da população de São Paulo. Mas, ao mesmo tempo que tu estivesses com a população, estudando, refletindo e buscando soluções para problemas locais tu estarias buscando a dimensão nacional, estadual, regional desses problemas. Mas o ponto de partida é o hoje. Eu te diria: o ponto de partida é o aqui e o agora. É a partir de aqui e agora que tu ganhas a generalização no tempo e no espaço.

\section{Sobre a autora}

Ivany Rodrigues Pino é Editora-chefe da Revista Educação \& Sociedade, Professora Dra. aposentada da Faculdade de Educação da UNICAMP. Graduação e mestrado em Serviço Social, Juiz de Fora (MG) e Rio de Janeiro (RJ); Graduação e mestrado em Sociologia na Universidade de Louvain la Neuve, na Bélgica; Doutorado em Sociologia da Educação pela Faculdade de Educação da UNICAMP. Susas áreas de pesquisa são: Sociologia da educação e Política educacional.

\section{Referência}

AVALONE FILHO, O.; NASIF, M. I.; BORCHERT, C. L. Paulo Freire volta a trabalhar no Brasil. Jornal da Educação, Campinas, n. 00, p. 3-5, abr. 1980.

Recebido: 22 jul. 2021

Aceito: 22 jul. 2021 